\title{
Decorating the carbon felt electrode with polymeric platinize nanocomposite: characterization and electrocatalytic activity towards methanol oxidation reaction
}

\author{
MOHAMMAD ALI KAMYABI*, KAJAL EBRAHIMI QARATAPEH, SALMA JADALI and \\ MOHSEN MOHARRAMNEZHAD \\ Department of Chemistry, Faculty of Science, University of Zanjan, 45371-38791 Zanjan, Iran \\ E-mail: kamyabi@znu.ac.ir
}

MS received 7 January 2019; revised 3 May 2019; accepted 6 May 2019

\begin{abstract}
Herein, carbon felt (CF), a porous carbonaceous material is used as an anode in a direct methanol fuel cell (DMFC) application. In order to enhance the electrochemical activity of this electrode, modification of the $\mathrm{CF}$ electrode is performed with a polymeric-platinize nanocomposite by a pure electrochemical method. In the modification process, 4-methyl-1,2-diaminobenzene is electropolymerized on the CF surface and then, $\mathrm{Pt}$ nanoparticles are electrodeposited on this substrate. Physical characteristics of the synthesized nanocomposite, $\mathrm{Pt} / \mathrm{p}-\mathrm{MDAB} / \mathrm{CF}$, are investigated by field emission scanning electron Microscopy and energy-dispersive Xray spectra. The electrochemical studies such as cyclic voltammetry, chronoamperometry, and electrochemical impedance spectroscopy prove the Pt/p-MDAB/CF superiority over Pt/CF towards methanol oxidation. This superiority that results from the cooperation effect between carbonaceous-polymeric layer and $\mathrm{Pt}$ nanoparticles, introduces $\mathrm{Pt} / \mathrm{p}-\mathrm{PDAB} / \mathrm{CF}$ as the suitable candidate anode for methanol oxidation reaction (MOR).
\end{abstract}

Keywords. Carbon felt; methanol oxidation reaction (MOR); Pt/p-MDAB/CF; onset potential.

\section{Introduction}

Electrochemical energy technology is an attempt to solve the energy crisis. It proposes the use of direct alcohol fuel cells (DAFCs) that convert the chemical energy of the light molecular weight alcohols such as methanol and ethanol into electrical energy. Direct methanol fuel cell (DMFC) is a propitious fuel cell because of the methanol properties such as high energy density, low operation temperature, facile storage and environmental friendly. DMFC, due to inexpensive production and simple oxidation pathway of methanol, is more approved than a direct ethanol fuel cell (DEFC). ${ }^{1,2}$ The performance of the electrochemical oxidation of methanol that is more desirable than chemical oxidation, relies on the utilized catalyst. ${ }^{3,4}$ So far, researchers have paid more attention to the methanol oxidation on the Pt-based catalysts. ${ }^{5}$ Methanol oxidation reaction (MOR) on the Pt-based catalyst is performed by cleavage of C-H and $\mathrm{O}-\mathrm{H}$ bonds (Scheme 1). The poisoning of Pt-based catalysts with species such as $\mathrm{CO}, \mathrm{HCHO}, \mathrm{HCOOH}$ and $\mathrm{CO}_{2}$ that are produced through MOR are strongly adsorbed

\footnotetext{
*For correspondence
}

on the catalyst surface and decrease the electrochemical performance of the catalyst by prevention of methanol adsorption. Therefore, high cost, low stability, and broad tendency to the agglomeration are the preventive factors against the spread employing of Pt-based catalysts. .,6,7 $^{4}$ The synthesis of bimetallic catalysts, ${ }^{4,8}$ non-Pt catalysts, ${ }^{9}$ and decoration of a surveyed substrate with $\mathrm{Pt}$ nanoparticles are the remedies against defects of Ptbased catalysts.

The kinetics of methanol oxidation in the alkaline medium is more desirable than the acidic medium. This desirability explains the different role of adsorbed $\mathrm{OH}$ $\left(\mathrm{OH}_{\mathrm{ads}}\right)$ species in the methanol oxidation in two mediums. In the acidic medium, $\mathrm{OH}_{\text {ads }}$ species inhibit from methanol adsorption while in the alkaline medium facilitate the binding of methanol on the active sites of the catalyst. So, the alkaline medium offers more desirable kinetics of methanol oxidation than acidic medium. ${ }^{10}$

The use of the porous materials with high surface area as the electrode decreases the value of Pt loading and restricts agglomeration of $\mathrm{Pt}$ nanoparticles. Fabrication of Raney-type electrodes ${ }^{11}$ is one of the ways for the enlargement of the surface porosity, but the usage of carbon felt (CF) electrode as an electrode is an economical 


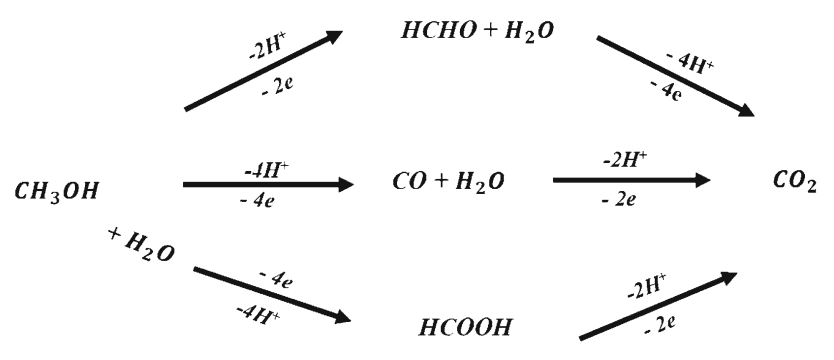

Scheme 1. The mechanism illustration of methanol oxidation in acidic media.

way for the accretion of porosity and surface area. ${ }^{12}$ The properties of CF electrodes such as low price, high stability, surface area, conductivity and porosity ${ }^{13}$ have led to their usage in the different fields such as Vanadium redox flow batteries (VRFB), ${ }^{14}$ biofuel cell (BFC), ${ }^{15}$ microbial fuel cells (MFC), ${ }^{16}$ capacitors - supercapacitors, ${ }^{17}$ and Lithium-ion batteries(LIB). ${ }^{18}$ However, the low price of $\mathrm{CF}$ converts it into an economical material in electrochemical fields, insufficient wettability and low electrochemical activity confine its electrochemical acting in the energy purposes. The modification of the surface that decreases polarization and increases the kinetics of electrochemical reactions is a required effort for the appropriate electrochemical performance of the CF electrodes. ${ }^{19}$ The utilization of the conducting polymers as the support for Pt nanoparticles is another promising approach to overcome the accumulation of these nanoparticles and, decrease noble metal consumption. The conductive polymers have won deep attentions at different electrochemical branches such as electrocatalysis, ${ }^{20}$ sensors, ${ }^{21-24}$ and corrosion protection ${ }^{25}$ since revolutionary reconnaissance. Different approaches such as chemical, electrochemical and photo-initiating can be adopted to prepare these polymers. Electropolymerization is a suitable method that forms a polymeric layer with controllable thickness and charge transfer characteristics with an economical procedure. ${ }^{26,27}$ In the electropolymerization method, the growth of the polymeric film can be controlled by different effective parameters such as the number of potential sweeps, scan rate, and monomer concentration. ${ }^{28}$ Recently, the conductive polymers such as polypyrrole, ${ }^{29}$ polyaniline, ${ }^{30}$ polyindole ${ }^{31}$ due to their properties like facile oxidation of their monomers, high redox property and conductivity have been studied in the different electrochemical fields. ${ }^{28}$

In the present study, modified $\mathrm{CF}$ with poly-4methyl-1,2-diaminobenzene (p-MDAB) was used as the substrate for deposition of Pt nanoparticles. The electropolymerization method was used for the production of the polymeric layer and the effective parameters on the polymeric film growth were investigated. By using the electrodeposition methods such as square wave current, square wave potential, cyclic voltammetry, and constant current pulse electrodeposition, $\mathrm{Pt}$ nanoparticles with suitable size and morphology are selectively deposited on desirable location of the substrate. ${ }^{6}$ Surface morphology of the modified CF with the synthesized nanocomposite $(\mathrm{Pt} / \mathrm{p}-\mathrm{MDAB} / \mathrm{CF})$ was inspected by FESEM and EDX analysis. The excellent electrocatalytic performance of $\mathrm{Pt} / \mathrm{p}-\mathrm{MDAB} / \mathrm{CF}$ towards MOR in the acidic media recommends $\mathrm{Pt} / \mathrm{p}$ $\mathrm{MDAB} / \mathrm{CF}$ as the magnificent candidate anode in the DMFC.

\section{Experimental}

\subsection{Materials}

All of the analytical grade materials without additional purification were used. $\mathrm{MeOH}(99.6 \%), \mathrm{H}_{2} \mathrm{SO}_{4}$ (95-97\%), $\mathrm{K}_{2} \mathrm{PtCl}_{6}$ and 4-methyl-1,2-diaminobenzene were purchased from Merck (Darmstadt, Germany). $\mathrm{CF}\left(\sim 1.1 \mathrm{~cm}^{2}\right)$ was purchased from Liyuan Co (Changsha, China). Fuel cell grade commercial Pt/C (10 wt\% Platinum on Vulcan xc 72) was bought from Sainergy (USA).

\subsection{Decoration the CF electrode with Pt/ $p-M D A B$ nanocomposite}

Before modification of $\mathrm{CF}$ surface, it was cleaned in an ultrasonic bath with $\mathrm{HCl}$, acetone and double distilled water respectively. The electropolymerization of 4-methyl1,2-diaminobenzene on the $\mathrm{CF}$ substrate was performed by immersing the cleaned CF in $10 \mathrm{~mL}$ acidic solution of $6 \mathrm{mM}$ monomer. The electropolymerization process was performed by 13 consecutive cycles at a sweep rate of $40 \mathrm{mV} \mathrm{s}^{-1}$ in the potentials range of -0.6 to $0.9 \mathrm{~V}$. To synthesis $\mathrm{Pt} / \mathrm{p}-\mathrm{MDAB}$ nanocomposite, $\mathrm{CV}$ experiment in the $7 \mathrm{mM}$ acidic solution of $\mathrm{K}_{2} \mathrm{PtCl}_{6}$ was performed. The consecutive cycles of 30 at a sweep rate of $50 \mathrm{mV} \mathrm{s}^{-1}$ in the potentials range of -0.5 to $0.5 \mathrm{~V}$ were optimum conditions for the formation of $\mathrm{Pt}$ nanoparticles on the modified CF surface. ${ }^{32}$

\subsection{Physical and electrochemical characterization}

Field emission scanning electron microscopy (FESEM, TESCAN/Vega3, Czech Republic), energy-dispersive X-ray spectra (EDS, TESCAN/Vega3, Czech Republic) were chosen methods for investigation of the morphology and chemical composition of decorated CF electrode. The total of loaded Pt was determined by the inductively coupled plasma optical emission spectroscopy (ICP-OES, Perkin Elmer, Optima 7300DV, USA). Micro-Autolab potentiostat/galvanostat 101, controlled by Nova software supplied (Autolab, Switzerland) by a three-electrode system was used for cyclic voltammetry 

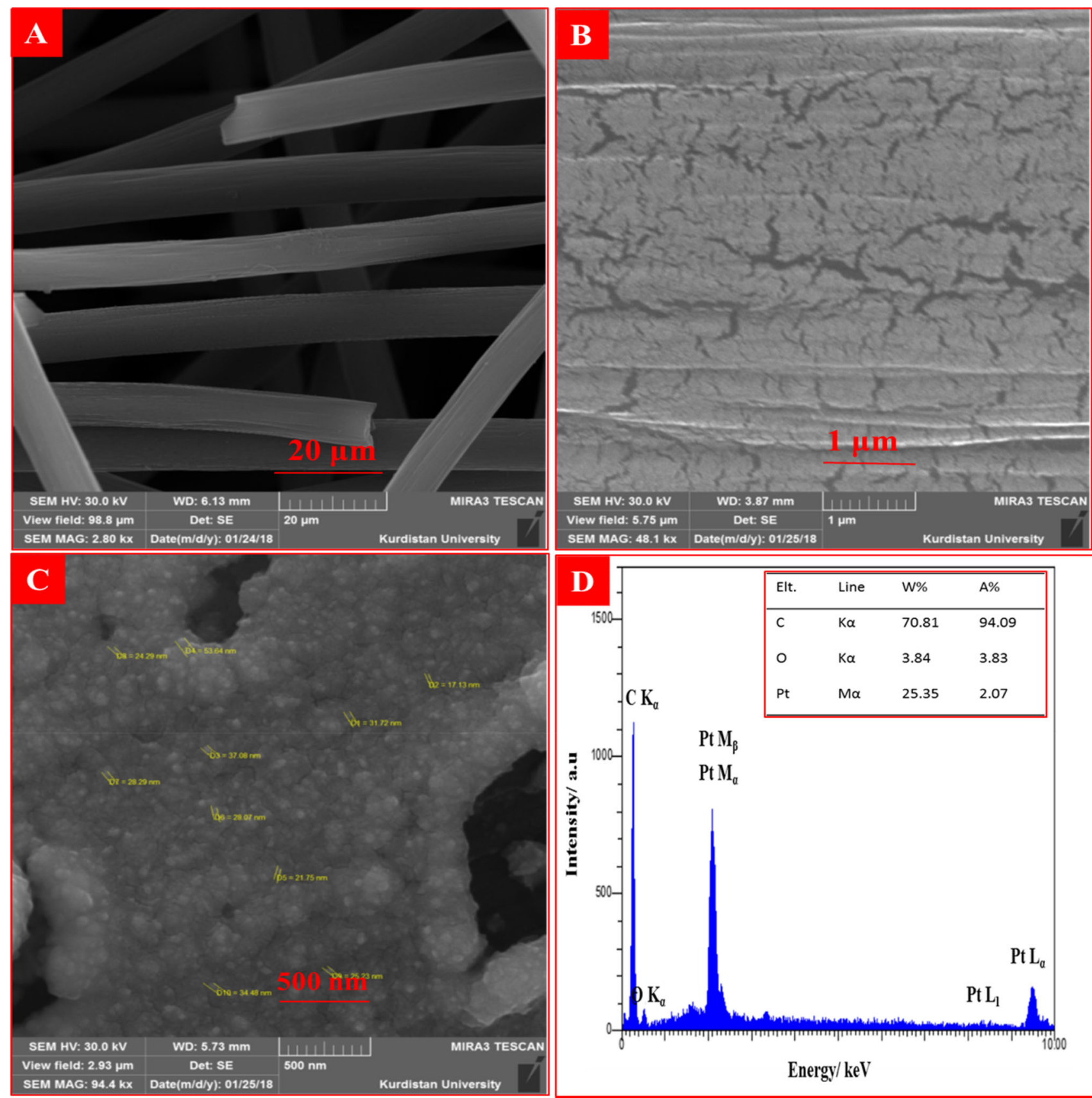

Figure 1. FESEM images of $\mathrm{CF}(\mathrm{A}), \mathrm{p}-\mathrm{MDAB} / \mathrm{CF}(\mathrm{B}), \mathrm{Pt} / \mathrm{p}-\mathrm{MDAB} / \mathrm{CF}(\mathrm{C})$ and EDX spectrum of Pt/p-MDAB/CF (D).

(CV) and chronoamperometry (CA) experiments. The standard three-electrode system was composed of the $\mathrm{Ag} / \mathrm{AgCl}$ (saturated $\mathrm{KCl}$ ), $\mathrm{Pt} / \mathrm{p}-\mathrm{MDAB} / \mathrm{CF}$ and $\mathrm{Pt}$ wire as the reference, working and counter electrode respectively. The connection of the modified CF with the electrochemical cell was adjusted by a stainless steel needle. Electrochemical experiments were done in a mixture of $0.5 \mathrm{M} \mathrm{H}_{2} \mathrm{SO}_{4}$ and $1 \mathrm{M}$ methanol at a scan rate of $50 \mathrm{mV} \cdot \mathrm{s}^{-1}$. Electrochemical impedance spectroscopy (EIS) was accomplished in a solution of $0.1 \mathrm{M} \mathrm{NaOH}$ containing $5 \mathrm{mM} \mathrm{K}_{3}\left[\mathrm{Fe}(\mathrm{CN})_{6}\right]$ with a frequency range of $100 \mathrm{kHz}$ to $0.01 \mathrm{~Hz}$. (Zahner Ennium, Germany).

\section{Results and Discussion}

\subsection{Surface characterization}

The surface morphology of Pt/p-PDAB modified CF electrode was considered by FESEM and EDX analysis. FESEM images of CF fibers are observed in Figure 1A. There is enough empty space through the CF cylinder that produces a distinct structure for this carbonaceous material. ${ }^{16}$ The FESEM image of the modified CF with 
the polymeric layer in the optimum condition presents the perfect formation of a proper substrate for distribution of Pt nanoparticles (Figure 1B). The distribution of $\mathrm{Pt}$ nanospheres with the diameter between 37 and $17 \mathrm{~nm}$ have been revealed in Figure 1C. EDX spectrum exhibits an elemental analysis of the modified CF electrode. The covering of the polymeric film with the $\mathrm{Pt}$ nanoparticles is proved by the EDX analysis. The signal peaks of $\mathrm{C}$ and $\mathrm{O}$ at 0.2 and $0.5 \mathrm{keV}$ are shown. The signal peaks of Pt at 2.2, 8.5 and $9.5 \mathrm{keV}$ demonstrate the presence of these nanoparticles on the electrode surface. The elemental composition of the synthesized catalyst has been reported in the inset of Figure 1D.

\subsection{Electrochemical inspection of the modified catalyst}

The electrochemical surface area (ECSA) is a valuable parameter that expresses the number of electrochemically active sites. The characterization of synthesized catalyst for ECSA calculation was performed by CV experiment in $0.5 \mathrm{M} \mathrm{H}_{2} \mathrm{SO}_{4}$ saturated with $\mathrm{N}_{2}$ gas and the potential range of $-0.2 \mathrm{~V}$ to $1 \mathrm{~V} v s \mathrm{Ag} / \mathrm{AgCl}$ at the scan rate of $20 \mathrm{mV} . \mathrm{s}^{-1}$. The saddle-shaped redox peaks that are related to the adsorption/desorption of hydrogen on the catalyst surface are revealed in the potential range from $-0.2 \mathrm{~V}$ to $0.1 \mathrm{~V}$. For the synthesized Pt-based catalyst, the Pt oxidation peak appears around $0.3 \mathrm{~V}$ and the Pt oxide monolayer reduction peak appears at $0.46 \mathrm{~V}$. Finally, the ECSA of the Pt-based catalyst is determined on the basis of the following equation $1 .^{7,33}$

$$
E C S A=\frac{Q_{1}}{m_{P t} \times Q_{2}}
$$

Where $\mathrm{Q}_{1}\left(\mathrm{mC} . \mathrm{cm}^{-2}\right)$ is the coulombic charge that is determined by the integration of the hydrogen adsorption-desorption region in the $\mathrm{CV}$ curve, $\mathrm{m}_{\mathrm{Pt}}(\mathrm{g}$. $\mathrm{cm}^{-2}$ ) is the loading of $\mathrm{Pt}$ nanoparticles on the electrode surface, and $\mathrm{Q}_{2}\left(0.21 \mathrm{mC} . \mathrm{cm}^{-2}\right)$ is the coulombic charge required for the oxidation of the single layer of hydrogen coverage on Pt surface area. The ECSA value for $\mathrm{Pt} / \mathrm{p}-\mathrm{MDAB} / \mathrm{CF}$ is calculated at $84.5 \mathrm{~m}^{2}$. $\mathrm{g}_{\mathrm{pt}}^{-1}$ that is about 5.3 fold greater than commercial $\mathrm{Pt} / \mathrm{C}$. The high ECSA value of $\mathrm{Pt} / \mathrm{p}-\mathrm{MDAB} / \mathrm{CF}$ brings the accretion electrochemical activity of $\mathrm{Pt}$ catalyst on the decorated CF.

To consider the electrochemical performance of modified CF towards oxidation of methanol, the cyclic voltammograms of different catalysts were recorded in $\mathrm{N}_{2}$-saturated solution containing $0.5 \mathrm{M} \mathrm{H}_{2} \mathrm{SO}_{4}+1 \mathrm{M}$ $\mathrm{MeOH}$ in the potential range of $0 \mathrm{~V}$ to $1 \mathrm{~V}$ and at the scan rate of $50 \mathrm{mV}^{-1}{ }^{-1}$. The cyclic voltammograms of methanol oxidation on the surface of $\mathrm{Pt} / \mathrm{p}-\mathrm{MDAB} / \mathrm{CF}$,

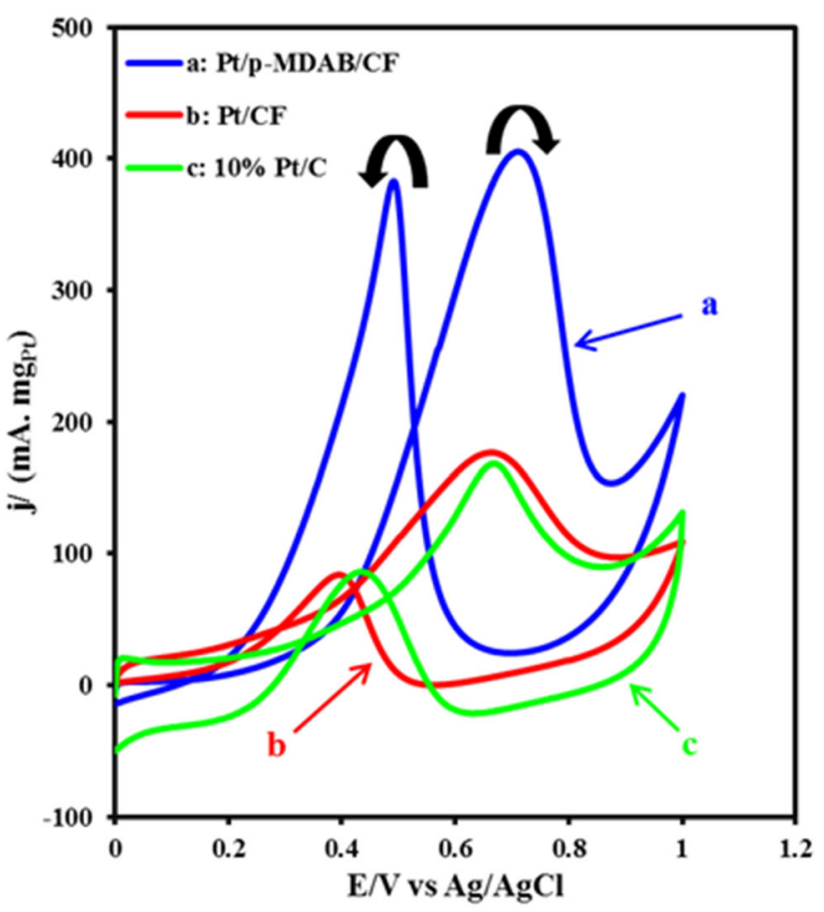

Figure 2. Cyclic voltammograms of a: Pt/p-MDAB/CF, b: $\mathrm{Pt} / \mathrm{CF}$ and c: commercial $10 \% \mathrm{Pt} / \mathrm{C}$ in $\mathrm{N}_{2}$-saturated $0.5 \mathrm{M}$ $\mathrm{H}_{2} \mathrm{SO}_{4}+1 \mathrm{M} \mathrm{MeOH}$ at the scan rate of $50 \mathrm{mV}^{-\mathrm{s}^{-1}}$.

$\mathrm{Pt} / \mathrm{CF}$ and commercial $\mathrm{Pt} / \mathrm{C}$ have been compared in Figure 2. The onset potential $\left(\mathrm{E}_{\text {onset }}\right)$, forward peak current, and the ratio of the forward to the backward current $\left(\mathrm{I}_{\mathrm{f}} / \mathrm{I}_{\mathrm{b}}\right)$ are the significant parameters obtained from CV studies. These parameters have been manifested in Table 1 at length and have been explicated in the following controversy. The typical curves with the forward and backward peaks are seen for each Ptbased catalyst. The forward peak current is related to the methanol oxidation and the backward peak current corresponds to the oxidation of intermediate that is produced in the forward potential scan. Some of the species such as $\mathrm{CO}, \mathrm{HCOO}^{-}$are the primary intermediates and another species such as $\mathrm{HCHO}$ and $\mathrm{HCOOH}$ are the secondary intermediates. ${ }^{34-36}$ The $\left(\mathrm{I}_{\mathrm{f}} / \mathrm{I}_{\mathrm{b}}\right)$ ratio is the criterion for the antipoisoning property of catalyst. The high value of $I_{f} / I_{b}$ for the synthesized catalyst indicates the wealthy methanol oxidation and high tolerance towards poisoning phenomenon on the catalyst surface. ${ }^{37}$ As is comprehended from Figure 2, the current density is insignificant at the lower potential of $0.2 \mathrm{~V} v$ s. $\mathrm{Ag} / \mathrm{AgCl}$ in the forward potential sweep. Just as potential is swept to the more positive, the current density increase and a peak in the potential of about $0.71 \mathrm{~V}$ vs. $\mathrm{Ag} / \mathrm{AgCl}$ appears. The lower onset potential, the potential where the sharp increase in the oxidation current is observed, and the higher mass activity 


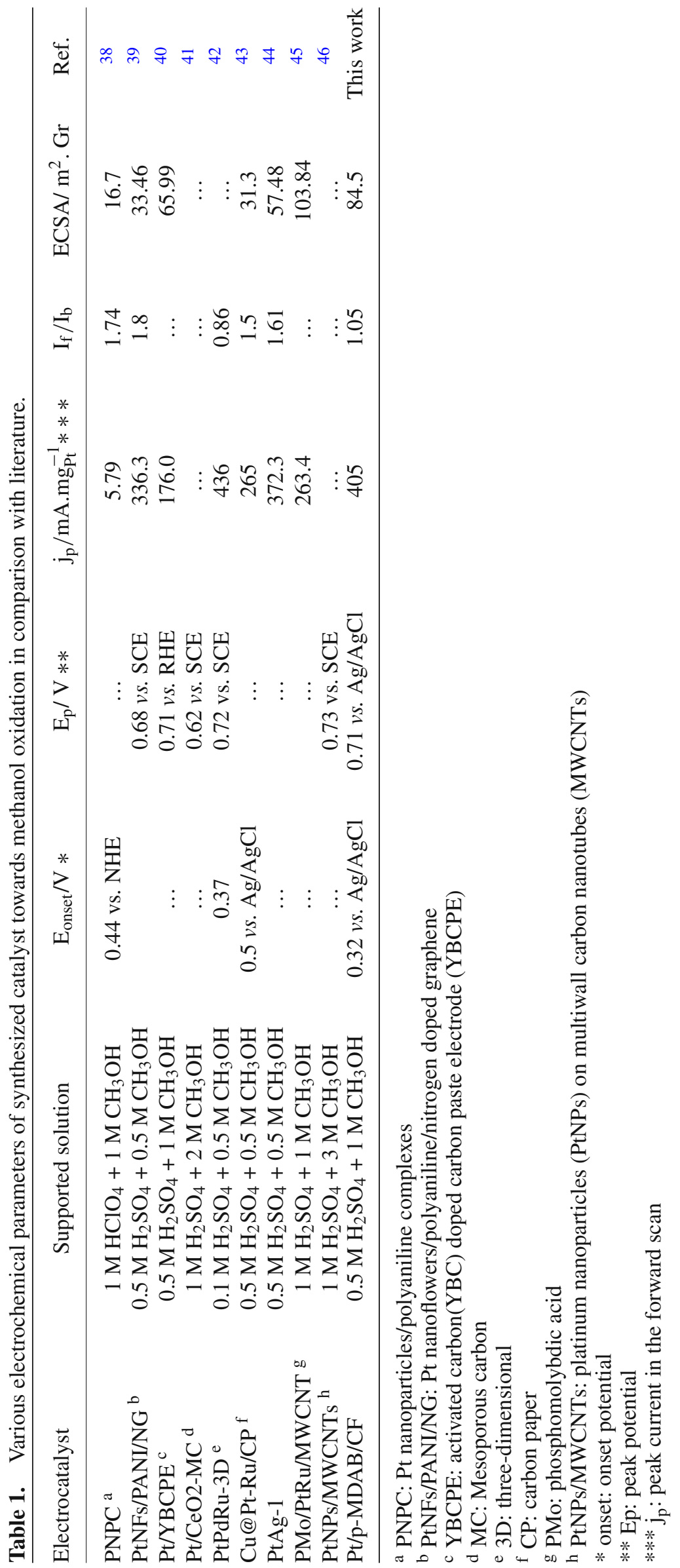



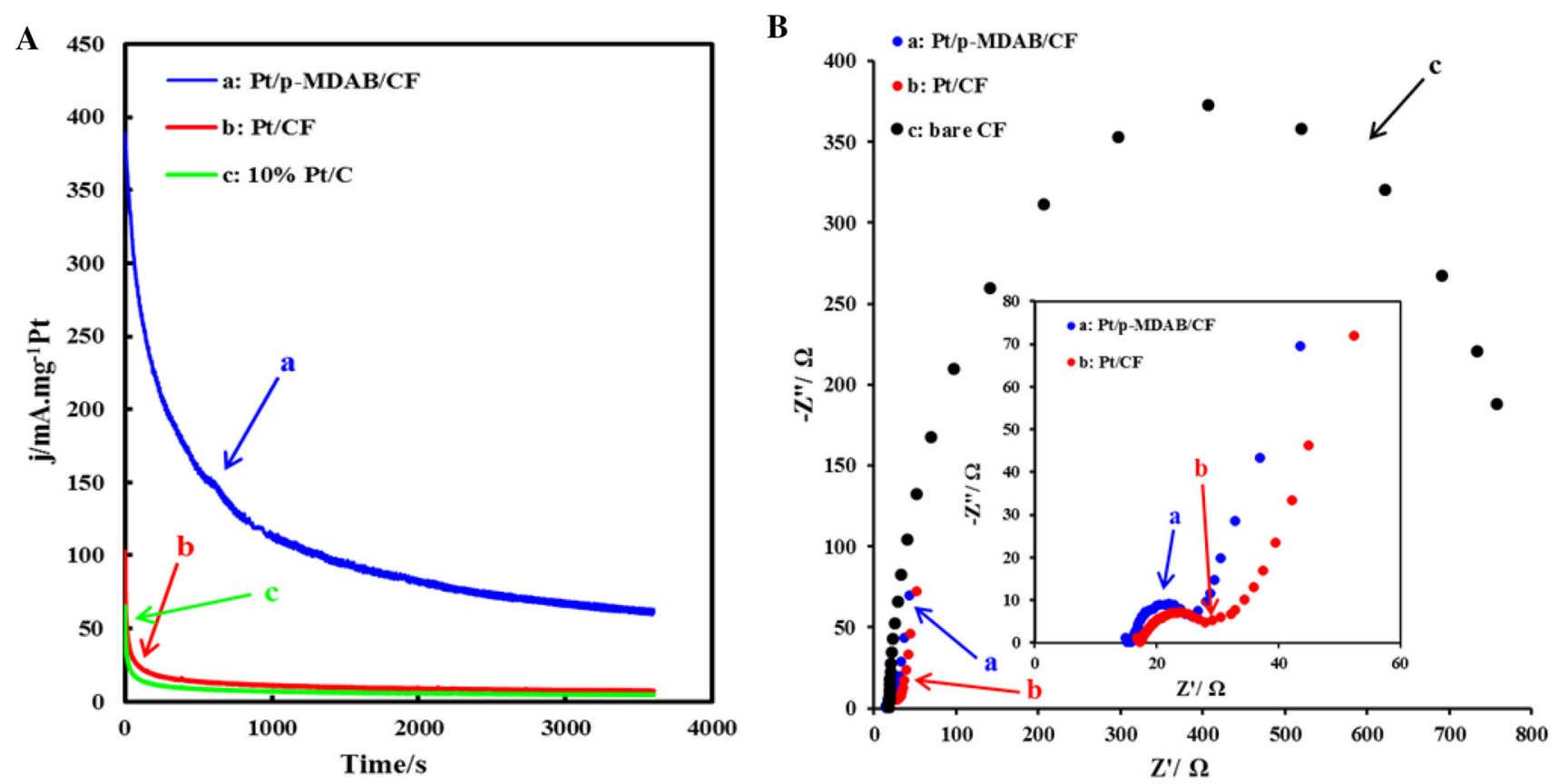

Figure 3. (A) Chronoamperometric curves of a: Pt/p-MDAB/CF, b: Pt/CF and c: commercial $10 \% \mathrm{Pt} / \mathrm{C}$ in $\mathrm{N}_{2}-\mathrm{saturated}$ $0.5 \mathrm{M} \mathrm{H}_{2} \mathrm{SO}_{4}+1 \mathrm{M} \mathrm{MeOH}$ (B) Nyquist plots of a: Pt/p-MDAB/CF, b: Pt/CF and c: bare $\mathrm{CF}$ in $0.1 \mathrm{M} \mathrm{NaOH}$ containing $1.0 \mathrm{mM} \mathrm{K}_{3} \mathrm{Fe}(\mathrm{CN})_{6}$ at open circuit potential (OCP). The inset image in (B) shows the local enlargement of Nyquist plots for a: Pt/p-MDAB/CF and b: Pt/CF.

for $\mathrm{Pt} / \mathrm{p}-\mathrm{MDAB} / \mathrm{CF}$ prove the more preferable electrochemical performance of synthesized catalyst than the commercial Pt/C towards MOR. Furthermore, the $\mathrm{I}_{\mathrm{f}} / \mathrm{I}_{\mathrm{b}}$ ratio for $\mathrm{Pt} / \mathrm{p}-\mathrm{MDAB} / \mathrm{CF}$ is 1.05 which demonstrates the superior antipoisoning property of synthesized catalyst. The excellent performance of $\mathrm{Pt} / \mathrm{p}-\mathrm{MDAB} / \mathrm{CF}$ can result from the contribution of polymeric film and $\mathrm{CF}$ that produce high porous and conductive substrate for the distribution of Pt nanoparticles with the scanty agglomeration.

The deliberation of the longtime stability for Pt/p$\mathrm{MDAB} / \mathrm{CF}$ was done by (CA) method. The current-time curves on the surface of $\mathrm{Pt} / \mathrm{p}-\mathrm{MDAB} / \mathrm{CF}, \mathrm{Pt} / \mathrm{CF}$ and commercial $\mathrm{Pt} / \mathrm{C}$ in $\mathrm{N}_{2}$-saturated solution of $0.5 \mathrm{M} \mathrm{H}_{2}$ $\mathrm{SO}_{4}+1 \mathrm{M} \mathrm{MeOH}$ have been represented in the Figure 3A. The CA curves manifest the typical image that current continually decreases and earn a steady state. The current decay arises from the adsorption of the poisoning intermediates which are produced in MOR procedure on the catalyst surface. ${ }^{47,48}$ Although both the Pt-based catalysts exhibit the still decay of current, the more moderate current density and the higher current density in the steady state condition for Pt/p-MDAB/CF after testing for $3600 \mathrm{~s}$ demonstrates the durability and antipoisoning desirability of Pt/p-MDAB modified CF electrode in DMFC.

Electrochemical impedance spectroscopy (EIS) presents reliable information for charge-transfer kinetics in catalyst-electrolyte surface and electrode capacitance. ${ }^{49}$ Figure $3 \mathrm{~B}$ analogize EIS spectrum of $\mathrm{Pt} / \mathrm{p}-\mathrm{MDAB} / \mathrm{CF}, \mathrm{Pt} / \mathrm{CF}$ and bare CF electrodes. A typical EIS spectrum which is often entitled the Nyquist plot is organized from one semicircle portion with small diameter in the high frequency along with enlarged one in the low frequency. The diameter of the semicircle in the high and low frequency depend on the charge transfer resistance $\left(\mathrm{R}_{\mathrm{ct}}\right)$ and the intermediates adsorption on the electrode surface respectively. ${ }^{12,28,49-51}$ A large hemicycle in the high frequency certifies the sluggish MOR kinetics due to intermediates adsorption on the electrode surface. This phenomenon causes the poor kinetics by the blocking of the electroactive sites and inhibition of the continuous methanol adsorption. ${ }^{52}$ On the other hand, a small hemicycle witnesses low value of impedance as a result of a large effective surface area and the charge transfer. ${ }^{46}$ As observed in the Figure 3B, the smaller diameter of the semicircle in the high frequency for the modified CF electrode with the synthesized nanocomposite exhibits the lower charge transfer resistance and faster kinetics for the methanol oxidation on the $\mathrm{Pt} / \mathrm{p}-\mathrm{MDAB} / \mathrm{CF}$. It is an apparent indication of the collaboration of Pt nanoparticles and high porous polymeric-carbonaceous substrate. This collaboration decreases the interfacial charge transfer resistance and increases the MOR kinetics for $\mathrm{Pt} / \mathrm{p}-\mathrm{MDAB} / \mathrm{CF}$. 


\section{Conclusions}

In this project, the surface of the $\mathrm{CF}$ electrode was successfully decked with the Pt/p-MDAB nanocomposite through a simple, fast and effectual electrochemical method. The polymeric layer covered the surface of CF electrode without an adherent material. Pt nanoparticles were uniformly electrodeposited on the $\mathrm{p}-\mathrm{MDAB} / \mathrm{CF}$. The morphological studies demonstrated that the surface of the CF electrode has been properly covered with the synthesized nanocomposite. The electrochemical findings indicated that MOR can be enhanced on the surface of the CF electrode with the modification by $\mathrm{Pt} / \mathrm{p}-\mathrm{MDAB}$ nanocomposite. Consequently, the proper electrochemical parameters of this catalyst that is relevant to the cooperation effect of polymericcarbonaceous substrate and Pt nanoparticles for production of the large ECSA recommends $\mathrm{Pt} / \mathrm{p}-\mathrm{MDAB} / \mathrm{CF}$ as the beneficial anode in DMFC.

\section{Acknowledgements}

Authors would like to thank the University of Zanjan Research Council for support of this work.

\section{References}

1. Wang J, Cheng N, Banis M N, Xiao B, Riese A and Sun X 2015 Comparative study to understand the intrinsic properties of $\mathrm{Pt}$ and $\mathrm{Pd}$ catalysts for methanol and ethanol oxidation in alkaline media Electrochim. Acta 185267

2. Katikawong P, Ratana T and Veerasai W 2009 Temperature dependence studies on the electro-oxidation of aliphatic alcohols with modified platinum electrodes $J$. Chem. Sci. 121329

3. Liu Y, Chen Y, Li S, Shu C Y, Fang Y and Song B 2018 Improved charge transfer in a $\mathrm{Mn}_{2} \mathrm{O}_{3} @ \mathrm{Co}_{1.2} \mathrm{Ni}_{1.8} \mathrm{O}_{4}$ hybrid for highly stable alkaline direct methanol fuel cells with good methanol tolerance ACS Appl. Mater. Inter. 109485

4. Rajathi M P, Sivakumar C and Berchmans S 2018 Methanol electro-oxidation by nanostructured $\mathrm{Pt} / \mathrm{Cu}$ bimetallic on poly 3,4 ethylenedioxythiophene (PEDOT) Electrochim. Acta $\mathbf{2 8 2} 163$

5. Lei F, Li Z, Ye L, Wang Y and Lin S 2016 Onepot synthesis of $\mathrm{Pt} / \mathrm{SnO}_{2} / \mathrm{GNs}$ and its electro-photosynergistic catalysis for methanol oxidation Int. J. Hydrogen Energy $\mathbf{4 1} 255$

6. Yea F, Xu C, Liu G, Yuan M, Wang Z, Du X and Lee J K 2018 Effect of pulse electrodeposition parameters on electrocatalytic the activity of methanol oxidation and morphology of Pt/C catalyst for direct methanol fuel cells Energy Convers. Manage. 16085

7. Sha R and Badhulika S 2018 Effect of pulse electrodeposition parameters on electrocatalytic the activity of methanol oxidation and morphology of $\mathrm{Pt} / \mathrm{C}$ catalyst for direct methanol fuel cells J. Electroanal. Chem. 8209
8. Yang J, Tan X, Qian Y, Li L, Xue Y, Dai Z, Wang H, Qu W and Chu Y 2016 Methanol oxidation on Pt/CeO $2 @$ C$\mathrm{N}$ electrocatalysts prepared by the in-situ carbonization of polyvinylpyrrolidone J. Appl. Electrochem. 46 779

9. Li J, Luo Z, Zuo Y, Liu J, Zhang T, Tang P, Arbiol J, Llorca J and Cabot A 2018 NiSn bimetallic nanoparticles as stable electrocatalysts for methanol oxidation reaction Appl. Catal. B Environ. 23410

10. Mehek R, Iqbal N, Noor T, Nasir H, Mehmood Y and Ahmed S 2017 Novel Co-MOF/graphene oxide electrocatalyst for methanol oxidation Electrochim. Acta $\mathbf{2 5 5}$ 195

11. Solmaz R, Salcı A, Yüksel H, Doğrubaş M and Kardaş G 2017 Preparation and characterization of Pd-modified Raney-type NiZn coatings and their application for alkaline water electrolysis Int. J. Hydrogen Energy 42 2464

12. Demir D D, Salcı A and Solmaz R 2018 Fabrication of Mo-modified carbon felt as candidate substrate for electrolysis: Optimization of $\mathrm{pH}$, current and metal amount Int. J. Hydrogen Energy 4310540

13. Le T X H, Bechelany M and Cretin M 2017 Carbon felt based-electrodes for energy and environmental applications: A review Carbon 122564

14. Kim Y, Choi Y Y, Yun N, Yang M, Jeon Y, Kim K J and Choi J 2018 Activity gradient carbon felt electrodes for vanadium redox flow batteries J. Power Sources 408128

15. Le T X H, Bechelany M, Engel A B, Cretin M and Tingry S 2016 Gold particles growth on carbon felt for efficient micropower generation in a hybrid biofuel cell Electrochim. Acta 219121

16. Christwardana M, Frattini D, Accardo G, Yoon S P and Kwon Y 2018 Early-stage performance evaluation of flowing microbial fuel cells using chemically treated carbon felt and yeast biocatalyst Appl. Energy 222 369

17. Jung $\mathrm{J}$ and $\mathrm{Kim} \mathrm{D} H 2018 \mathrm{~W}_{18} \mathrm{O}_{49}$ nanowires assembled on carbon felt for application to supercapacitors Appl. Surf. Sci. 433750

18. Shen X, Cao Z, Zhang J, Li T and Jiang W 2018 In-situ loading of $\mathrm{ZnO}$ nanoparticles on carbon felt as novel binder-free flexible anode for high performance lithiumion batteries Mater. Lett. 22993

19. Moghim M H, Eqra R, Babaiee M, Zarei-Jelyani M and Loghavi M M 2017 Role of reduced graphene oxide as nano-electrocatalyst in carbon felt electrode of vanadium redox flow battery J. Electroanal. Chem. 78967

20. Li Y, Li T, Yan L, An L, Yao S and Zhang Z 2018 Fabrication and characterizations of $\mathrm{PdAu} /$ thiolation poly (phthalazinone ether ketone) superfine fibrous membrane as a free-standing electrocatalyst for methanol oxidation Electrochim. Acta 289397

21. Kamyabi M A, Hajari N, Turner A P and Tiwari A 2013 A high-performance glucose biosensor using covalently immobilised glucose oxidase on a poly(2,6-diaminopyridine)/carbon nanotube electrode Talanta 116801

22. Kamyabi M A and Rahmanian N 2015 An electrochemical sensing method for the determination of levodopa using a poly(4-methylortho-phenylenediamine)/MWNT modified GC electrode Anal. Methods 71339 
23. Kamyabi M A and Kahe H 2016 A high selective and simple electoanalytical method for simultaneous determination of dopamine, ascorbic acid and uric acid Sensor Lett. 141

24. Kamyabi M A and Shafiee M A 2012 Electrocatalytic oxidation of dopamine, ascorbic acid and uric acid at Poly-2,6-diaminopyridine on the surface of carbon nanotubes/GC electrodes J. Braz. Chem. Soc. 19

25. Jiang L, Syed J A, Lu H and Meng X 2019 In-situ electrodeposition of conductive polypyrrole-graphene oxide composite coating for corrosion protection of 304SS bipolar plates J. Alloys Compd. 77035

26. Chen S, Liu S, Wen A, Zhang J, Nie H, Chen J, Zeng R, Long Y, Jin Y and Mai R 2018 New insight into electropolymerization of melamine. I: Chloride promoted growth of polymelamine in different $\mathrm{pH}$ medium Electrochim. Acta 271312

27. Siwal S, Matseke S, Mpelane S, Hooda N, Nandi D and Mallick K 2017 Palladium-polymer nanocomposite: An anode catalyst for the electrochemical oxidation of methanol Int. J. Hydrogen Energy 4223599

28. Kesavan S, Kumar D R, Baynosa M L and Shim J J 2018 Potentiodynamic formation of diaminobenzene films on an electrochemically reduced graphene oxide surface: Determination of nitrite in water samples Mater. Sci. Eng. C 8597

29. Merati Z, Parsa J B and Babaei-Sati R 2018 Electrochemically synthesized polypyrrole/MWCNTs- $\mathrm{Al}_{2} \mathrm{O}_{3}$ ternary nanocomposites supported $\mathrm{Pt}$ nanoparticles toward methanol oxidation Int. J. Hydrogen Energy 43 20993

30. Wu G, Li L, Li J H and Xu B Q 2005 Polyaniline-carbon composite films as supports of Pt and PtRu particles for methanol electrooxidation Carbon 432579

31. Zhou W, Du Y, Ren F, Wang C, Xu J and Yang P 2010 High efficient electrocatalytic oxidation of methanol on Pt/polyindoles composite catalysts Int. J. Hydrogen Energy 353270

32. Zhou H H, Jiao S Q, Chen J H, Wei W Z and Kuang Y F 2004 Effects of conductive polyaniline (PANI) preparation and platinum electrodeposition on electroactivity of methanol oxidation J. Appl. Electrochem. 34455

33. Wang Z, Zhang F, Zou H, Yuan Y, Wang H, Xia J and Wang Z 2018 Preparation of a Pt/NiFe layered double hydroxide/reduced graphene oxide composite as an electrocatalyst for methanol oxidation J. Electroanal. Chem. 818198

34. Dinesh B and Saraswathi R 2016 Enhanced performance of Pt and Pt-Ru supported PEDOT-RGO nanocomposite towards methanol oxidation Int. J. Hydrogen Energy 41 13448

35. Zhao H, Yang J, Li L, Li H, Wang J and Zhang Y 2009 Effect of over-oxidation treatment of $\mathrm{Pt}-\mathrm{Co} /$ polypyrrolecarbon nanotube catalysts on methanol oxidation Int. J. Hydrogen Energy 343908

36. Chen D, Zhao Y, Peng X, Wang X, Hu W, Jing C, Tian S and Tian J 2015 Star-like PtCu nanoparticles supported on graphene with superior activity for methanol electrooxidation Electrochim. Acta 17786

37. Kung C C, Lin P Y, Xue Y, Akolkar R, Dai L, Yu X and Liu C C 2014 Three dimensional graphene foam supported platinum-ruthenium bimetallic nanocatalysts for direct methanol and direct ethanol fuel cell applications J. Power Sources 256329

38. Yan R, Jin B, Li D, Zheng J, Li Y and Qian C 2018 One-step electrochemically co-deposited Pt nanoparticles/polyaniline composites with raspberry structures for methanol electro-oxidation Synth. Met. 235 110

39. Luo S, Chen Y, Xie A, Kong Y, Tao Y, Pan Y and Yao C 2015 Synthesis of PtNFs/PANI/NG with enhanced electrocatalytic activity towards methanol oxidation Ionics 211277

40. Zhang Y, Li F, Liu X, Lu J and Zhang G 2017 Promoting influence of activated carbon used in carbon paste electrode on platinum nanoparticles efficiency in methanol electrooxidation Electrochim. Acta 242165

41. Zaidi S J, Bello M, Al-Ahmed A, Bin Yousaf A and Imran M 2017 Mesoporous carbon supported Pt/MO2 ( $\mathrm{M}=\mathrm{Ce}, \mathrm{Pr}, \mathrm{Nd}, \mathrm{Sm})$ heteronanostructure: Promising non-Ru methanol oxidation reaction catalysts for direct methanol fuel cell application J. Electroanal. Chem. 794 86

42. Yang Y, Luo L M, Zhang R H, Du J J, Shen P C, Dai Z X, Sun C and Zhou X W 2016 Free-standing ternary PtP$\mathrm{dRu}$ nanocatalysts with enhanced activity and durability for methanol electrooxidation Electrochim. Acta 222 1094

43. Poochai C, Veerasai W, Somsook E and Dangtip S 2016 Dealloyed ternary Cu@Pt-Ru core-shell electrocatalysts supported on carbon paper for methanol electrooxidation catalytic activity Electrochim. Acta $\mathbf{2 2 2}$ 1243

44. Li J, Rong H, Tong X, Wang P, Chen $\mathrm{T}$ and Wang Z 2018 Platinum-silver alloyed octahedral nanocrystals as electrocatalyst for methanol oxidation reaction J. Colloid Surface A $\mathbf{5 1 3 2 5 1}$

45. Jin X, He B, Miao J, yuan J, Zhang Q and Niu L 2012 Stabilization and dispersion of PtRu and Pt nanoparticles on multiwalled carbon nanotubes using phosphomolybdic acid, and the use of the resulting materials in a direct methanol fuel cell Carbon 503083

46. Ghartavol H M, Moakhar R S and Dolati A 2017 Electrochemical investigation of electrodeposited platinum nanoparticles on multi walled carbon nanotubes for methanol electro-oxidation J. Chem. Sci. 129 1399

47. Cao J, Chen Z, Xu J, Wang W and Chen Z 2013 Mesoporous carbon synthesized from dual colloidal silica/block copolymer template approach as the support of platinum nanoparticles for direct methanol fuel cells Electrochim. Acta $\mathbf{8 8} 184$

48. Yang F, Zhang B, Dong S, C, Wang, Feng A, Fan X and Li Y 2019 Reduced graphene oxide supported Pd-CuCo trimetallic catalyst: Synthesis, characterization and methanol electrooxidation properties J. Energy Chem. 29 72

49. Shah A A, Yasmeen N, Rahman G and Bilal S 2017 High electrocatalytic behaviour of $\mathrm{Ni}$ impregnated conducting polymer coated platinum and graphite electrodes for electrooxidation of methanol Electrochim. Acta $\mathbf{2 2 4}$ 468

50. Ghiabi C, Ghaffarinejad A, Kazemi H and Salahandish R 2018 In situ, one-step and co-electrodeposition 
of graphene supported dendritic and spherical nanopalladium-silver bimetallic catalyst on carbon cloth for electrooxidation of methanol in alkaline media Renew. Energy 1261085

51. Kamyabi M A, Mohammadian H, Jadali S and Moharramnezhad M 2019 Hydrothermal syntheses of NiO-GO nanocomposite on 3D nickel foam as a support for Pt nanoparticles and its superior electrocatalytic activity towards methanol oxidation, accepted for publication in Electroanalysis https://doi.org/10.1002/elan. 201800793

52. Gorle D B, Kumman V V and Kulandainathan M A 2017 Highly efficient, large surface area and spherically shaped Pt particles deposited electrolytically synthesized graphene for methanol oxidation with impedance spectroscopy Int. J. Hydrogen Energy 4216258 